\title{
Conservative management following closed reduction of traumatic anterior dislocation of the shoulder (Review)
}

\author{
Handoll HHG, Hanchard NCA, Goodchild LM, Feary J
}

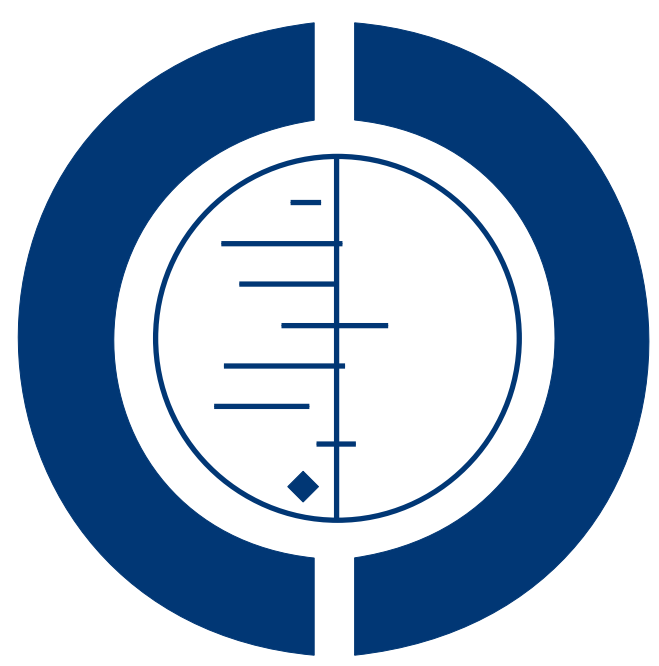

\section{THE COCHRANE COLLABORATION $^{\circledR}$}

This is a reprint of a Cochrane review, prepared and maintained by The Cochrane Collaboration and published in The Cochrane Library 2009, Issue 1

http://www.thecochranelibrary.com

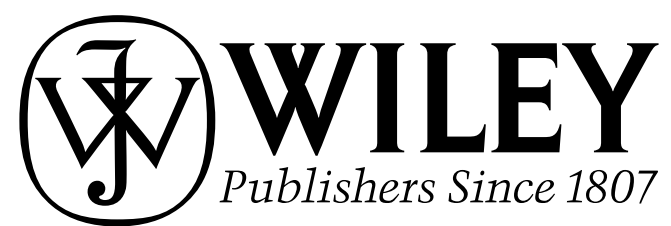

Conservative management following closed reduction of traumatic anterior dislocation of the shoulder (Review)

Copyright (@) 2009 The Cochrane Collaboration. Published by John Wiley \& Sons, Ltd. 
TABLE OF CONTENTS

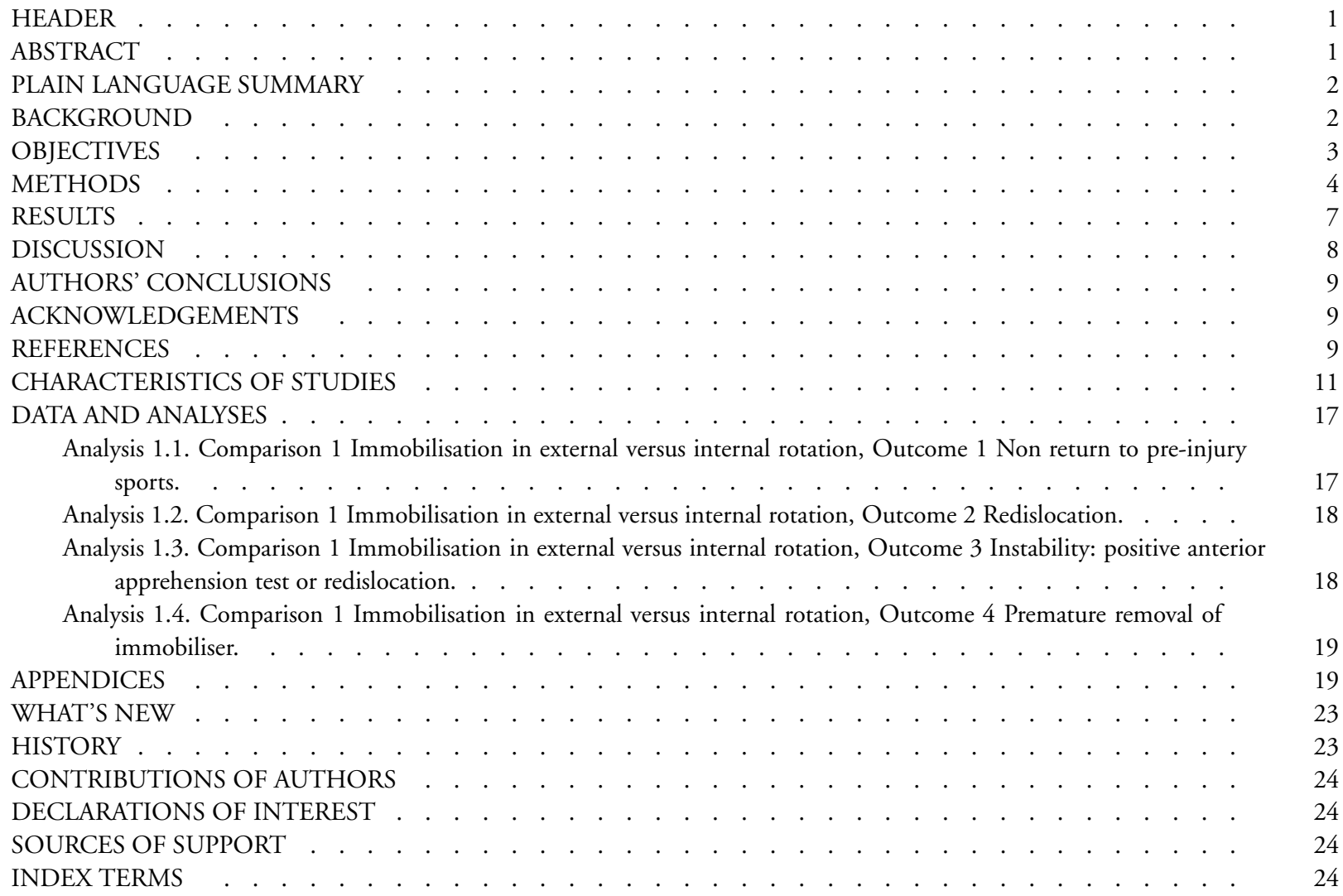




\title{
Conservative management following closed reduction of traumatic anterior dislocation of the shoulder
}

\author{
Helen HG Handoll ${ }^{2}$, Nigel CA Hanchard ${ }^{1}$, Lorna M Goodchild ${ }^{3}$, Joy Feary ${ }^{4}$ \\ ${ }^{1}$ Centre for Rehabilitation Sciences, Research Institute for Health Sciences and Social Care, Middlesbrough, UK. ${ }^{2}$ Centre for Rehabil- \\ itation Sciences (CRS), Research Institute for Health Sciences and Social Care, University of Teesside, Middlesborough, UK. ${ }^{3}$ Dept of \\ Physiotherapy, South Tees NHS Trust, Middlesbrough, UK. ${ }^{4}$ Dept of Physiotherapy, North Tees NHS Trust, Stockton, UK
}

Contact address: Nigel CA Hanchard, Centre for Rehabilitation Sciences, Research Institute for Health Sciences and Social Care, University of Teesside, School of Health and Social Care, Middlesbrough, Tees Valley, TS1 3BA, UK. n.hanchard@tees.ac.uk. nigel.hanchard@ntlworld.com.

Editorial group: Cochrane Bone, Joint and Muscle Trauma Group.

Publication status and date: Edited (no change to conclusions), published in Issue 1, 2009.

Review content assessed as up-to-date: 3 November 2005.

Citation: Handoll HHG, Hanchard NCA, Goodchild LM, Feary J. Conservative management following closed reduction of traumatic anterior dislocation of the shoulder. Cochrane Database of Systematic Reviews 2006, Issue 1. Art. No.: CD004962. DOI: 10.1002/14651858.CD004962.pub2.

Copyright (C) 2009 The Cochrane Collaboration. Published by John Wiley \& Sons, Ltd.

\section{A B S T R A C T}

Background

Acute anterior dislocation is the commonest type of shoulder dislocation and usually results from an injury. Subsequently, the shoulder is less stable and more susceptible to redislocation, especially in active young adults.

\section{Objectives}

To compare methods of conservative (non-surgical) management versus no treatment or different methods of conservative management after closed reduction of traumatic anterior dislocation of the shoulder. Interventions include methods of postreduction immobilisation and rehabilitation.

\section{Search strategy}

We searched the Cochrane Bone, Joint and Muscle Trauma Group Specialised Register (March 2005), the Cochrane Central Register of Controlled Trials (The Cochrane Library Issue 3, 2005), MEDLINE, EMBASE, the National Research Register (UK), conference proceedings and reference lists of articles.

\section{Selection criteria}

Randomised or quasi-randomised controlled trials comparing various conservative interventions versus control (no or sham treatment) or other conservative interventions applied after closed reduction of traumatic anterior dislocation of the shoulder.

\section{Data collection and analysis}

All authors selected trials, assessed methodological quality and extracted data. Study authors were contacted for additional information. 


\section{Main results}

One flawed quasi-randomised trial was included. A "preliminary report" gave the results for 40 adults with primary traumatic anterior dislocation of the shoulder treated by post-reduction immobilisation with the arm in either external or internal rotation. There was no statistically significant difference between the two groups in the failure to return to pre-injury sports by previously active athletes, in redislocation or shoulder instability. Similar numbers of participants of the two groups removed their immobiliser before one week had passed.

\section{Authors' conclusions}

There is a lack of evidence from randomised controlled trials to inform the choices for conservative management following closed reduction of traumatic anterior dislocation of the shoulder.

Sufficiently powered, good quality, well reported randomised controlled trials with long-term surveillance of conservative management are required. In particular, trials examining the type and duration of immobilisation would be useful.

\section{PLAIN LANGUAGESUMMARY}

\section{Non-surgical management after non-surgical repositioning of traumatic anterior dislocation of the shoulder}

Acute anterior shoulder dislocation is an injury where the top end of the upper arm bone is pushed out of the joint socket in a forward direction. Afterwards, the shoulder is less stable and prone to redislocation, especially in active young adults. Initial treatment involves putting the joint back; this is called 'reduction'. 'Closed reduction' refers to cases where this is done without surgery. Subsequent treatment is often conservative (non-surgical), and generally involves placing the injured arm in a sling or other immobilising device followed by exercises.

After a comprehensive search for randomised controlled trials that compared different methods of conservative management for these injuries, we included only one small trial. This compared immobilisation of the arm in either external rotation (where the arm was orientated outwards with the forearm away from the chest) or internal rotation (the usual sling position where the arm rests against the chest) following closed reduction. Preliminary results for 40 adults showed no statistically significant difference between the two groups in terms of previously active athletes' return to pre-injury sports, nor in redislocation or shoulder instability. Similar numbers of participants in each of the two groups removed their immobiliser before one week had passed. This multicentre trial was flawed by its use of inadequate methods of allocating patients to the trial intervention groups and its inadequate assessment of outcome.

In conclusion, there is a lack of evidence from randomised controlled trials to inform the choices for conservative management following closed reduction of traumatic anterior dislocation of the shoulder.

\section{B A C K G R O U D}

Anterior dislocation of the shoulder is where the head of the humerus (the top end of the upper arm bone) is displaced out of the shoulder (gleno-humeral) joint in a forward direction. The extent of dislocation varies from partial dislocation (subluxation) to full dislocation where the joint surfaces completely lose contact. Primary (first-time) dislocation generally results from trauma (injury), typically during contact sports in adolescents and younger adults. In older adults it may result from a fall from standing height. Shoulder dislocation may be in other directions, posterior, for example, and result from other causes such as spontaneous dislocation, perhaps due to congenital joint laxity. Traumatic anterior dislocation is the commonest type and accounts for $96 \%$ of all shoulder dislocations (Goss 1988).

A study based in the USA (Simonet 1984) found an overall adjusted incidence of initial traumatic shoulder dislocation of 8.2 per 100,000 person-years, and estimated the incidence of all trau- 
matic shoulder dislocations, initial and recurrent, to be at least 11.2 per 100,000 person-years. Simonet 1984 estimated prevalence expressed in terms of a cumulative incidence rate of $0.7 \%$ for men and $0.3 \%$ for women up to the age of 70 years. Another study, based in Sweden (Hovelius 1982), found that 35 (1.7\%) of 2092 randomly selected people aged 18 to 70 years had experienced shoulder dislocation. Though the overall male to female ratio was three to one, the ratio was nine to one in the 21 to 30 age group and, conversely, one to three in the 50 to 70 age group. Although shoulder dislocation is generally considered an injury of young adults, Rowe 1956 found that there were as many initial dislocations after age 45 as before age 45 . Twenty per cent of 545 consecutive patients presenting with anterior shoulder dislocation were aged 60 years or more in Gumina 1997.

Once dislocation has occurred, the shoulder is less stable and more susceptible to redislocation. Recurrent dislocation tends to be more common in younger adults. For instance, a 10-year follow up evaluation found that $66 \%$ of those aged between 12 and 22 years at the time of their first dislocation had one or more recurrences; whereas it was $24 \%$ of those aged between 30 and 40 years (Hovelius 1996). Gumina 1997 found single or multiple recurrences in $22 \%$ of those aged 60 years or more.

The nature and extent of the damage to the soft tissue surrounding the shoulder joint from a traumatic anterior dislocation vary. Common presentations include the Bankart lesion, where the capsule surrounding the shoulder joint peels away from its attachment to the scapula (Bankart 1938), and the Hill Sachs lesion, which involves a compression fracture of the humeral head as well as damage to its overlying cartilage (Hill 1940).

The aims of treatment for anterior dislocation are to restore a functional, painless and stable shoulder. The choice of treatment approach will be influenced by patient age and previous history of dislocation, occupation, level of activity, general health, ligamentous laxity and expectations of patient adherence to a prescribed therapeutic regime. Traditionally, a non-surgical (conservative) approach, comprising closed reduction, three to six weeks' immobilisation in a sling, and subsequent physiotherapy or physical therapy programme (O'Brien 1987) has been used for first time dislocation. Surgical intervention has generally been reserved for chronic recurrence/instability. However, a Cochrane review (Handoll 2004) comparing surgical with non-surgical treatment found some limited evidence supporting primary surgery for young adults, usually male, engaged in highly demanding physical activities who have sustained their first acute traumatic shoulder dislocation. Our review considers the various approaches to postreduction conservative treatment, such as the duration and position of sling immobilisation, the modalities used, and the timing and extent of rehabilitation interventions.

\section{O B J E C T I V E S}

In this review we aimed to test the following null hypotheses for patients who have had closed reduction for traumatic anterior dislocation of the shoulder.

(1) No difference exists between outcomes from the different methods (including arm position) and durations (including none or intermittent) of postreduction immobilisation.

(2) No difference exists between outcomes from the provision of rehabilitation intervention (of any kind) versus no intervention.

The rehabilitation intervention could comprise a single modality (e.g. advice for home exercises or hydrotherapy) or be multicomponent. While potentially available to all patients allocated the rehabilitation intervention, its actual application may vary according to the perceived needs of individual patients.

We aimed to test this hypothesis separately for the provision of any rehabilitation (a) during immobilisation, and (b) after immobilisation.

(3) No difference exists between outcomes from different types of rehabilitation interventions.

This covers comparisons of different rehabilitation interventions: either different single modalities or different combinations of rehabilitation modalities. However, trials comparing variants of a particular modality would not have been considered unless the modality itself had been evaluated.

(4) No difference exists between outcomes from different methods of delivering/providing various rehabilitation interventions.

We planned to test this overall hypothesis separately for different comparisons. These would have included supervised therapy versus home exercises, different methods of supervised therapy (e.g. individual versus group instruction), and the frequency and duration of rehabilitation. In the first instance, we did not plan to include comparisons of rehabilitation intervention delivered by individual professionals (e.g. doctors, physiotherapists and occupational therapists) with different levels or backgrounds of expertise or training.

If the data had been available, we had planned to test the following hypotheses:

People with a first time dislocation have a different outcome to those with a recurrent dislocation.

Physically active young to middle-aged adults have a different outcome to those, such as older sedentary adults, who do not fall into this category.

Physically active young adults engaged in highly demanding physical activities who have sustained their first traumatic shoulder dislocation have a different outcome to those who do not fall into this category. 


\section{METHODS}

\section{Criteria for considering studies for this review}

\section{Types of studies}

We considered any randomised or quasi-randomised (for example, allocation by hospital record number or date of birth) controlled trials making comparisons stated in 'Objectives'.

\section{Types of participants}

Individuals who have undergone closed reduction for traumatic anterior dislocation of the shoulder. Ideally, the acute anterior shoulder dislocation should have been confirmed by physical examination and radiography (X-ray) or, more rarely, some other imaging modality such as magnetic resonance imaging (MRI). We intended to consider the potential for misdiagnosis, such as a missed proximal humeral fracture, in trials in which the method of diagnosis is unspecified or based on physical examination alone. Though we stated we would include individuals of any age, as we anticipated we found no trials focusing specifically on the management of traumatic anterior dislocation in children.

We excluded or would have excluded trials focusing on the treatment of non-traumatic or habitual dislocations, or concomitant fractures or multiple trauma; or those focusing on the management of neurovascular complications or postsurgical management. We stipulated that, unless separate data for acute traumatic anterior dislocations are provided, trials with mixed populations involving any one indication of the above would be considered for inclusion provided the proportion of the latter (e.g. atraumatic dislocation) is clearly defined for each treatment group and clearly small $(<$ $10 \%)$.

\section{Types of interventions}

We planned to include randomised trials of different methods, positions, durations and extent of immobilisation of the injured arm following closed reduction of traumatic anterior dislocation of the shoulder. We also planned to include randomised trials evaluating rehabilitation as part of the conservative treatment of these injuries. Examples of rehabilitation interventions are advice and education, active and passive mobilisation, proprioception and stabilisation exercises, scapular setting, and trunk stability exercises. These may be used in combination or individually, and applied in various ways and settings.

We planned to exclude trials comparing different techniques, timing (duration, frequency) and intensity of single rehabilitation modalities until the effectiveness of the modality itself has been examined. Also excluded would have been trials evaluating pharmacological interventions or trials testing interventions solely aimed at pain relief.

\section{Types of outcome measures}

\section{Primary outcomes}

We sought the following primary outcome measures.

(1) Recovery defined as return to pre-injury level of activity (sports/ work): (a) yes/no; (b) time to return.

(2) Re-injury or recurrence (including subsequent surgery): (a) yes/no; (b) time to reinjury or recurrence.

(3) Persistent pain (long-term).

(4) Subjective instability.

(5) Results from patient functional assessment measures such as Short Form-36 (SF-36), the Disability of the Arm, Shoulder, and Hand questionnaire (DASH) and other validated shoulder rating scales.

\section{Secondary outcomes}

We also sought the following secondary outcomes.

(6) Objective instability (e.g. apprehension test).

(7) Range of movement.

(9) Muscle strength.

(10) Complications (e.g. sensory or motor deficit, osteoarthritis).

(11) Satisfaction.

(12) Adherence to allocated treatment.

In addition, note was taken of any reports of service utilisation or resource use; for instance, length of hospital stay, outpatient attendance and the provision and nature of physiotherapy.

\section{Search methods for identification of studies}

We searched the Cochrane Bone, Joint and Muscle Trauma Group Specialised Register (March 2005), the Cochrane Central Register of Controlled Trials (CENTRAL) (The Cochrane Library, Issue 3, 2005), MEDLINE (1966 to August 2005), EMBASE (1980 to week 36 2005), CINAHL (1982 to August 2005), PEDro - physiotherapy evidence database at http://www.pedro.fhs.usyd.edu.au/ index.html (9 September 2005), OTseeker - The Occupational Therapy Systematic Evaluation of Evidence Database at http:/ /www.otseeker.com (9 September 2005), the UK National Research Register at http://www.update-software.com/national (Issue 3,2005) and reference lists of articles. No language restrictions were applied.

We also searched the conference proceedings of the British Elbow and Shoulder Society (2003, 2004 and 2005) and handsearched conferences proceedings published in the supplements of the Journal of Bone and Joint Surgery - British Volume (2004 and 2005, up to supplement 2) and Injury (2004).

In MEDLINE (OVID-WEB) the subject-specific strategy was combined with the first two stages of the revised Cochrane trial search strategy (Higgins 2005) (see Appendix 1). This subjectspecific strategy was modified for use in The Cochrane Library 
(see Appendix 2), EMBASE (see Appendix 3) and CINAHL (see Appendix 4).

\section{Data collection and analysis}

Two authors (NH and $\mathrm{HH}$ ) independently assessed potentially eligible trials for inclusion. These were checked by the other two authors. There was no disagreement. Titles of journals, names of authors or supporting institutions were not masked at any stage. All four authors independently assessed the methodological quality of the only included study and extracted data. The intended piloting of forms was curtailed since there was only one trial. Discrepancies were resolved through discussion.

We attempted to contact trialists of unpublished randomised controlled trials listed in the National Research Register (UK) for information on the current status of their trial, and Kiviluoto 1980 for details of methods. We corresponded with Prof Itoi on his trial (Itoi 2003).

\section{Quality assessment}

A modification of the Cochrane Bone, Joint and Muscle Trauma Group quality assessment tool (see Group module in The Cochrane Library) was used in the evaluation of the included studies. Table 1 shows the scoring scheme based on 12 aspects of trial methodology.

Table 1. Methodological quality assessment tool

\begin{tabular}{lll}
\hline Item & Scores & Notes \\
\hline $\begin{array}{l}\text { A. Was the assigned treatment adequately } \\
\text { concealed prior to allocation? }\end{array}$ & $\begin{array}{l}2 \text { = method did not allow disclosure of as- } \\
\text { signment. } \\
1=\text { small but possible chance of disclosure } \\
\text { of assignment or unclear. } \\
0 \text { = quasi-randomised or open list/tables. }\end{array}$ & $\begin{array}{l}\text { Coch sure }=\mathrm{B} \\
\text { Clearly Yes } \mathrm{A}\end{array}$ \\
& $\begin{array}{l}\text { Clearly No }=\mathrm{C} . \\
\end{array}$ \\
\hline
\end{tabular}

B. Were the outcomes of participants who withdrew described and included in the analysis (intention to treat)?

2 = withdrawals well described and accounted for in analysis.

$1=$ withdrawals described and analysis not possible.

$0=$ no mention, inadequate mention, or obvious differences and no adjustment.

C. Were the outcome assessors blinded to $2=$ effective action taken to blind assessors. treatment status?

$1=$ small or moderate chance of unblinding of assessors, or some blinding of outcomes attempted.

$0=$ not mentioned or not possible.

D. Were important baseline characteristics reported and comparable?
2 = good comparability of groups, or confounding adjusted for in analysis.

$1=$ confounding small, mentioned but not adjusted for, or comparability reported in
The principal confounders considered will be age, time since injury, primary or repeat dislocation, previous upper-arm in- 
Table 1. Methodological quality assessment tool (Continued)

text without confirmatory data.

$0=$ large potential for confounding, or not discussed. jury, presence of other shoulder injuries, hand dominance and type of sporting activity.
E. Were the participants blind to assignment status after allocation?
2 = effective action taken to blind participants.

$1=$ small or moderate chance of unblinding of participants.

$0=$ not possible, or not mentioned (unless double-blind), or possible but not done.
F. Were the treatment providers blind to assignment status?
2 = effective action taken to blind treatment providers.

$1=$ small or moderate chance of unblinding of treatment providers.

$0=$ not possible, or not mentioned (unless double-blind), or possible but not done.
G. Were care programmes, other than the trial options, identical?
2 = care programmes clearly identical.

1 = clear but trivial differences, or some evidence of comparability.

$0=$ not mentioned or clear and important differences in care programmes.
Examples of clinically important differences in care programmes: differences in the primary treatment intervention (type and duration of immobilisation), differences in call back times for assessment, and subsequent rehabilitation. These will depend on the interventions under test and the stage of treatment/rehabilitation.
$\mathrm{H}$. Were the inclusion and exclusion criteria for entry clearly defined?

I. Were the interventions clearly defined?

\section{$2=$ clearly defined interventio
with a standardised protocol.}

1 = clearly defined interventions are applied but the application protocol is not standardised.

$0=$ intervention and/or application proto-

col are poorly or not defined.

\section{J. Were the outcome measures used clearly 2 = clearly defined. defined? \\ $1=$ inadequately defined. \\ $0=$ not defined.}

K. Were the outcome measures/diagnostic $2=$ optimal.

tests used in outcome assessment appropri- $1=$ adequate. ate? 
Table 1. Methodological quality assessment tool (Continued)

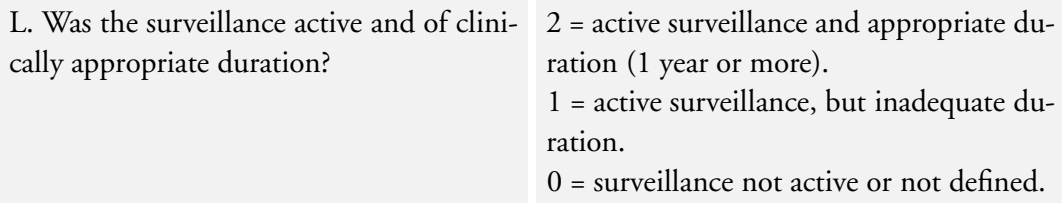

\section{Data analysis}

Where available and appropriate, quantitative data for outcomes listed in the inclusion criteria are presented graphically. Relative risks and $95 \%$ confidence intervals were calculated for dichotomous outcomes, and mean differences and 95\% confidence intervals calculated for continuous outcomes. Results of comparable groups of trials were pooled using the fixed-effect model and 95\% confidence intervals. Heterogeneity between comparable trials was tested using a standard chi-squared test and considered statistically significant at $\mathrm{P}<0.1$. Where there was some indication of heterogeneity, either from visual inspection of the results or based on the chi-squared test, we also quantified heterogeneity/ inconsistency using the I-squared statistic (Higgins 2003). Where there was significant heterogeneity, we viewed the results of the random-effects model and presented these when appropriate.

\section{Sensitivity and subgroup analyses}

Where appropriate, we intended to perform sensitivity analyses investigating the effects of allocation concealment, assessor blinding and loss to follow up. In addition we planned but did not carry out separate outcome analyses of (a) patients with primary dislocations compared with those with recurrent dislocations and (b) physically active young to middle-aged adults who constitute the main category of people at risk of this injury and those not falling into this category. Any tests of interaction calculated to determine if the results for subgroups were significantly different would have been based on odds ratio results.

\section{R E S U L T S}

\section{Description of studies}

See: Characteristics of included studies; Characteristics of excluded studies; Characteristics of ongoing studies.

We identified nine studies, only one (Itoi 2003) of which is included. Five studies were excluded, three (Hovelius 1983; Kiviluoto 1980; Xu 2003) of which are reported in full and two ( Harper 2000; Staply 2002) of which are listed only in the National
Research Register UK, and may not have started (see'Characteristics of excluded studies' table). Details of the other three trials (Itoi 2006; Pimpalnerker 2008; Wakefield 2001) are provided in the 'Characteristics of ongoing studies' table. A report for Wakefield 2001 is in preparation.

In Itoi 2003, post-reduction immobilisation of the affected arm in external rotation (essentially, the arm was orientated outwards with the forearm away from the chest) was compared with immobilisation in internal rotation (where the arm could rest against the chest). In the full report of this trial, there were 40 participants, of a mean age of 39 years, with primary anterior dislocation of the shoulder. A subsequent abstract (Itoi 2004) reported recruitment of 96 people and results for 80 of these. Correspondence with Prof Itoi revealed the trial is still ongoing and the results for 131 participants were presented in a lecture in 2005 . The study inclusion criteria differed between the preliminary and subsequent reports of this trial. We have selected the results from the full article for presentation in this version of the review, primarily because these are what are publicly available. Further details of this trial are given in the 'Characteristics of included studies' table.

\section{Risk of bias in included studies}

The scores for the 12 items rated in the quality assessment (see Table 1) for Itoi 2003 are shown below. With some exceptions, described below, these scores pertained to the full report (2003). A B C D E F G H I J K L Trial ID

010200111111 Itoi 2003

Treatment allocation (item A) in Itoi 2003 was on an alternating basis for the first 10 cases; a random numbers chart was used subsequently. Though withdrawals were described (item B), the later abstract report (Itoi 2004) did not present the numbers randomised in each group before the exclusion of 16 participants. There was no blinding of assessors (item C), trial participants (item E) or care providers (item F). The baseline characteristics (item D) were similar for the participants of the two treatment groups. There was some but incomplete evidence of comparability of care programmes (item G) for the two groups. The differences, as noted in the 'Characteristics of included studies' table, in the inclusion 
criteria (item $\mathrm{H}$ ) between the full report and subsequent abstract meant that this item was marked down. The description of the control intervention was inadequate (item I). Lastly, outcome definition (item J) and assessment (item K), and follow up were not optimal (item L). In particular, the recording of redislocation was by self-report of trial participants at different times, though on average at 15.5 months in the full report (and 12.4 months in the abstract report (Itoi 2004)).

\section{Effects of interventions}

As stated above, we present the results from the full article of Itoi 2003 in this version of the review. In their "preliminary report", Itoi 2003 gives the results for 40 people with primary traumatic anterior dislocation of the shoulder treated by post-reduction immobilisation with the arm in either external or internal rotation. Itoi 2003 provided no information on the overall return to preinjury activities. There was, however, no significant difference between the two groups in previously active athletes failing to return to their pre-injury sports (see Graph 01.01: relative risk (RR) 0.44, $95 \%$ confidence interval (CI) 0.11 to 1.81 ). Redislocation, at an average follow-up time of 15.5 months, was reported only by six participants of the internal rotation group (see Graph 01.02: RR 0.08 , $95 \%$ CI 0.00 to 1.28 ). Of those not reporting a redislocation, two people in each group tested positive for an anterior apprehension test used to assess anterior shoulder instability. The difference between the two groups in shoulder instability did not reach statistical significance (see Graph 01.03: RR 0.25, 95\% CI 0.06 to 1.03). Similar numbers of participants of the two groups removed their immobiliser before one week had passed (see Graph 01.04: RR 0.80, 95\% CI 0.25 to 2.55).

\section{DISCUSSION}

Despite our reasonably comprehensive search, we located very few potentially eligible studies and only included one of these, and this despite its poor methodology and presentation of "preliminary" findings. We located three other trials, presently described in the 'Characteristics of ongoing studies' table, whose results should appear in subsequent updates of this review. It is notable that but for the discovery of a report (published in 1999) providing a full description of the method of treatment allocation, one well-cited trial (Hovelius 1983) testing duration of immobilisation might have been included (see'Characteristics of excluded studies'). This shortage of randomised controlled trials parallels our experiences concerning the treatment of proximal humeral fractures (Handoll 2003) and the comparison of conservative versus surgical treatment for anterior dislocation of the shoulder (Handoll 2004), and is not unexpected.

We chose to include the results of the "preliminary report" of Itoi 2003 for several reasons. Firstly because this is the first and only published report of a promising technique (splinting in external rotation) that is gaining attention in the orthopaedic community. Secondly because the results are for the first phase of the trial and this may be considered a discrete study since, as apparent from the subsequent abstracts, the inclusion criteria for Itoi 2003 have now changed. Meanwhile, the suboptimal methods, in particular those of outcome assessment, do not appear to have changed and so the decision to include data from any further publication of this trial is not a foregone conclusion.

The standard treatment for traumatic anterior dislocation after closed reduction is immobilisation of the arm in a position of adduction and internal rotation. However, there is some evidence that this arm position could hinder "the anatomic healing of this injury" (Hart 2005). Itoi 2003 based the choice of external rotation upon magnetic resonance imaging observations that, where there has been traumatic separation of the glenoid labrum from underlying bone (the Bankart lesion), these structures are brought into better contact by external rather than internal rotation (Itoi 2001). Subsequent studies have supported this finding. Miller et al (Miller 2004) showed on cadaveric Bankart lesions that the contact force between the detached glenoid labrum and the underlying bone was maximal at 45 degrees of external rotation, diminishing to zero in internal rotation; and based on arthroscopic observations, Hart et al (Hart 2005) reported better contact in external compared with internal rotation in 23 out of 25 people with a Bankart lesion. Since contact between the torn surfaces would be expected to increase their capacity for reunion, these results lend support to Itoi's hypothesis that external rotation would decrease the recurrence rate. The study of Itoi 2003, however, does not provide the robust and sufficient evidence required to establish clinical benefit. As well as starting off using quasi-randomised methods and then insufficient methods to guarantee allocation concealment, the outcome assessment of Itoi 2003 is notably flawed. For instance, trials should measure the recovery to pre-injury levels of all participants and actively record recurrence at set times. Holding the arm in external rotation is more hazardous and awkward for people and so some better monitoring of acceptability, adherence and accidents should also be done. Particularly given that external rotation immobilisers are now available on the commercial market it is important that good quality randomised controlled trials of external rotation versus internal rotation are conducted by independent investigators.

Other issues remain relevant. These include the duration of immobilisation and method of rehabilitation. In particular, there is a lack of consensus of opinion regarding the duration of immobilisation and even whether immobilisation is necessary for older people who are at a much reduced risk of recurrence but a greater risk of shoulder stiffness (de Boer 2005).

The Cochrane review comparing surgical versus non-surgical treatment for anterior dislocation of the shoulder found some evidence from randomised controlled trials to support primary surgery in 
young adults (usually male) engaged in highly demanding physical activities who have sustained their first acute traumatic shoulder dislocation (Handoll 2004). There was no evidence available for other categories of patients. The review suggested that there is a need for randomised controlled trials comparing good standard surgical intervention versus good standard conservative treatment for primary anterior shoulder dislocation and anticipated that the present review of different conservative interventions including rehabilitation should provide important information in this area (Handoll 2004). The most important finding, however, of our review is the lack of good quality evidence to make any recommendations for practice or to inform on the best comparator for trials of surgical versus non-surgical management. If, in particular, the external rotation method fulfills its promise then it is likely this will impact on the decision to opt for surgical treatment. At present it is too early to say.

\section{A U THORS' CONCLUSIONS}

\section{Implications for practice}

There is a lack of evidence from randomised controlled trials to inform the choice of conservative management following closed reduction of traumatic dislocation of the shoulder.

\section{Implications for research}

There is a need for sufficiently powered, high quality and appropriately reported randomised controlled trials of key conservative treatment and rehabilitation options for traumatic anterior shoulder dislocation. These include trials comparing external rotation versus internal rotation, use and duration of immobilisation (for example, one versus three weeks), and timing for resumption of activities that may provoke a recurrence. For these trials, we suggest that some distinction should be made between young adults engaged in highly demanding physical activities who are at greater risk of recurrence, and older adults with a lower risk of recurrence but who are likely to have pre-existing degenerative disease of the rotator cuff. Attention should be given to outcome assessment in future trials. The use of well-defined and validated functional outcome measures, including patient-derived quality of life measures, is preferable. In addition, while blinding of interventions is not easy to do, concealed allocation should be done and, where possible, blinded outcome measurement as these would improve the quality and validity of future results.

\section{ACKNOWLEDGEMENTS}

We are very grateful to Lesley Gillespie for developing the search strategy for this review, for searching the Cochrane Bone, Joint and Muscle Trauma Group's Specialised Register and for her help during editorial processing. We thank Peter Herbison, Tracey Howe, Rocco Pitto and Janet Wale for their helpful feedback on the protocol. We thank Piet de Boer, Peter Herbison, Rajan Madhok and Janet Wale for their helpful feedback on the review.

We thank Eiji Itoi and Alison Wakefield for providing information on their trials, Mavis Luya for chasing up information on another trial and Yan Gong and Mingming Zwang for translation of the methods of a potential eligible study in Chinese.

Lorna Goodchild wishes to thank the Physiotherapy Research Foundation of the Chartered Society of Physiotherapy Charitable Trust (registered charity 279882) for financially supporting her involvement in this review.

\section{R E F E R E N C E S}

\section{References to studies included in this review}

\section{Itoi 2003 \{published data only\}}

Itoi E. personal communication July 102005.

* Itoi E, Hatakeyama Y, Kido T, Sato T, Minagawa H, Wakabayashi I, et al.A new method of immobilization after traumatic anterior dislocation of the shoulder: A preliminary study. Journal of Shoulder and Elbow Surgery 2003;12(5):413-5.

Itoi E, Hatakeyama Y, Kido T, Sato T, Minagawa H, Wakabayashi I, et al.A new method of immobilization in dislocation of the shoulder: a prospective randomized study [abstract]. Annual Meeting of the American Academy of Orthopaedic Surgeons; 2003 February 5-9; New Orleans [LA]. http://www.aaos.org/wordhtml/ anmt2003/sciprog/200.htm (accessed 01 October 2003).

Itoi E, Hatakeyama Y, Sato T, Kido T, Minagawa H, Wakabayashi

I, et al.Immobilization in external rotation after shoulder

dislocation: an interim report of an ongoing trial [abstract]. Annual
Meeting of the American Academy of Orthopaedic Surgeons; 2004 March 10-14; San Francisco (CA). http://www.aaos.org/wordhtml/ anmt2004/sciprog/071.htm (accessed 07 April 2004).

\section{References to studies excluded from this review}

\section{Harper 2000 \{unpublished data only\}}

Harper W. Anterior shoulder dislocations in the over 45 years of age. A prospective randomised study. In: National Resarch Register, Issue 1, 2005. Oxford: Update Software. Available from: http://www.nrr.nhs.uk/ViewDocument.asp?ID=N0122017162 (accessed 12 May 2005).

\section{Hovelius 1983 \{published data only\}}

Arciero RA, Taylor DC. Primary anterior dislocation of the shoulder in young patients. A ten-year prospective study [letter]. Journal of Bone and Joint Surgery - American Volume 1998;80(2):299-300. Hovelius L. Anterior dislocation of the shoulder in teenagers and 
young adults. Five year prognosis. Journal of Bone and Joint Surgery - American Volume 1987;69(3):393-9.

Hovelius L. The natural history of primary anterior dislocation of the shoulder in the young. Journal of Orthopaedic Science 1999;4 (4):307-17.

Hovelius L, Augustini BG, Fredin H, Johansson O, Norlin R, Thorling J. Primary anterior dislocation of the shoulder in young patients. A ten-year prospective study. Journal of Bone and Joint Surgery - American Volume 1996;78(11):1677-84.

* Hovelius L, Eriksson K, Fredin H, Hagberg G, Hussenius A, Lind $B$, et al.Recurrences after initial dislocation of the shoulder. Results of a prospective study of treatment. Journal of Bone and Joint Surgery - American Volume 1983;65(3):343-9.

Hovelius L, Lind B, Thorling J. Primary dislocation of the shoulder. Factors affecting the two-year prognosis. Clinical Orthopaedics and Related Research 1982;(176):181-5.

Kirkley S. Primary anterior dislocation of the shoulder in young patients. A ten-year prospective study [letter]. Journal of Bone and Joint Surgery - American Volume 1998;80(2):300-1.

\section{Kiviluoto 1980 \{published data only\}}

Kiviluoto O, Pasila M, Jaroma H, Sundholm A. Immobilization after primary dislocation of the shoulder. Acta Orthopaedica Scandinavica 1980;51(6):915-9.

Staply 2002 \{unpublished data only\}

Luya M. personal communication June 62005.

* Staply S. Anterior shoulder trial dislocation external rotation trial. In: National Resarch Register, Issue 1, 2005. Oxford: Update Software. Available from: http://www.nrr.nhs.uk/ ViewDocument.asp?ID=N0284109750 (accessed 12 May 2005).

\section{Xu 2003 \{published data only\}}

Xu Q, Gong Y, Lan Z, Xue C. Effects of systematic rehabilitation treatment on the stability of shoulder in young patients with shoulder dislocation. Zhongguo Linchuang Kangfu [Chinese Journal of Clinical Rehabilitation] 2003;14(7):2050-1.

\section{References to ongoing studies}

Itoi 2006 \{unpublished data only\}

Itoi E. personal communication July 122005.

Pimpalnerker 2008 \{unpublished data only\}

Pimpalnerker A. A comparison study of internal versus external rotation immobilisation for primary anterior shoulder dislocation. In: National Research Register, Issue 3, 2005. Oxford: Update Software. Available from: http://www.nrr.nhs.uk/ ViewDocument.asp?ID=N0523163139 (accessed 06 September 2005).

\section{Wakefield 2001 \{unpublished data only\}}

Wakefield A. personal communication June 242005.

* Wakefield A. The role of physiotherapy in the prevention of recurrence of anterior shoulder dislocation. In: National Research Register, Issue 1, 2005. Oxford: Update Software. Available from: http://www.nrr.nhs.uk/ViewDocument.asp?ID=N0519070803 (accessed 12 May 2005).

\section{Additional references}

\section{Bankart 1938}

Bankart AS. The pathology and treatment of recurrent dislocation of the shoulder joint. British Journal of Surgery 1938;26(101):23-9.

\section{de Boer 2005}

de Boer P. personal communication October 212005.

\section{Goss 1988}

Goss TP. Anterior glenohumeral instability. Orthopedics 1988;11 (1):87-95.

\section{Gumina 1997}

Gumina S, Postacchini F. Anterior dislocation of the shoulder in elderly patients. Journal of Bone and Joint Surgery - British Volume 1997;79(4):540-3.

\section{Handoll 2003}

Handoll HHG, Gibson JNA, Madhok R. Interventions for treating proximal humeral fractures in adults. Cochrane Database of Systematic Reviews 2003, Issue 1.[Art. No.: CD000434. DOI: 10.1002/14651858.CD000434]

\section{Handoll 2004}

Handoll HHG, Almaiyah MA, Rangan A. Surgical versus nonsurgical treatment for acute anterior shoulder dislocation. Cochrane Database of Systematic Reviews 2004, Issue 1.[Art. No.: CD004325. DOI: $10.1002 / 14651858 . C D 004325 . p u b 2]$

\section{Hart 2005}

Hart WJ, Kelly CP. Arthroscopic observation of capsulolabral reduction after shoulder dislocation. Journal of Shoulder and Elbow Surgery 2005;14:134-7.

\section{Higgins 2003}

Higgins JP, Thompson SG, Deeks JJ, Altman DG. Measuring inconsistency in meta-analyses. BMJ 2003;327:557-60.

\section{Higgins 2005}

Higgins JPT, Green S, editors. Highly sensitive search strategies for identifying reports of randomized controlled trials in MEDLINE. Cochrane Handbook for Systematic Reviews of Interventions 4.2.5 [updated May 2005]; Appendix 5b. In: The Cochrane Library, Issue 3, 2005. Chichester, UK: John Wiley \& Sons, Ltd.

\section{Hill 1940}

Hill HA, Sachs MD. The grooved defect of the humeral head: A frequently unrecognised complication of dislocations of the shoulder joint. Radiology 1940;35:690-700.

\section{Hovelius 1982}

Hovelius L. Incidence of shoulder dislocation in Sweden. Clinical Orthopaedics and Related Research 1982;(166):127-31.

\section{Hovelius 1996}

Hovelius L, Augustini BG, Fredin H, Johansson O, Norlin R, Thorling J. Primary anterior dislocation of the shoulder in young patients. A ten-year prospective study. Journal of Bone and Joint Surgery - American Volume 1996;78(11):1677-84.

Itoi 2001

Itoi E, Sashi R, Minagawa H, Shinizu T, Wakabayashi I, Sato K. Position of immobilization after dislocation of the glenohumeral joint. A study with use of magnetic resonance imaging. Journal of Bone and Joint Surgery - American Volume 2005;83(5):661-7. 


\section{Itoi 2004}

Itoi E, Hatakeyama Y, Sato T, Kido T, Minagawa H, Wakabayashi I, et al.Immobilization in external rotation after shoulder

dislocation: an interim report of an ongoing trial [abstract]. Annual Meeting of the American Academy of Orthopaedic Surgeons; 2004 March 10-14; San Francisco (CA). http://www.aaos.org/wordhtml/ anmt2004/sciprog/071.htm (accessed 07 April 2004).

\section{Miller 2004}

Miller BS, Sonnabend DH, Hatrick C, O'Leary S, Goldberg J,

Harper W, et al.Should acute anterior dislocations of the shoulder be immobilized in external rotation? A cadaveric study. Journal of Shoulder and Elbow Surgery 2004;13:589-92.

\section{O’Brien 1987}

O'Brien SJ, Warren RF, Schwartz EA. Anterior shoulder instability. Orthopedic Clinics of North America 1987;18(3):395-408.

Rowe 1956

Rowe CR. Prognosis in dislocation of the shoulder. Journal of Bone and Joint Surgery - American Volume 1956;38(5):957-77.

\section{Simonet 1984}

Simonet WT, Melton LJ II, Cofield RH, Ilstrup DM. Incidence of anterior shoulder dislocation in Olmsted County, Minnesota. Clinical Orthopaedics and Related Research 1984;(186):186-91.

* Indicates the major publication for the study 
CHARACTERISTICS OF STUDIES

\section{Characteristics of included studies [ordered by study ID]}

Itoi 2003

\begin{tabular}{|c|c|}
\hline Methods & $\begin{array}{l}\text { Method of randomisation: initially quasi-randomised using alternation (10 cases) then use of random } \\
\text { numbers chart } \\
\text { Assessor blinding: no } \\
\text { Intention-to-treat analysis: no information } \\
\text { Loss to follow up: none }\end{array}$ \\
\hline Participants & $\begin{array}{l}4 \text { departments of orthopaedic surgery in Japan } \\
40 \text { participants (see Notes) } \\
\text { Inclusion criteria: primary anterior dislocation with or without greater tuberosity or glenoid fracture. } \\
\text { Exclusion criteria: fractured greater tuberosity remaining displaced and treated surgically after manual } \\
\text { reduction of the dislocation. (Glenoid fractures were not mentioned.) } \\
\text { Sex: } 29 \text { male, } 11 \text { female } \\
\text { Age: mean } 39 \text { years, range } 17-84 \text { years } \\
\text { Assigned: } 20 / 20 \text { (group A/B) } \\
\text { Assessed: } 20 / 20 \text { (at final follow up) }\end{array}$ \\
\hline Interventions & $\begin{array}{l}\text { Group A: immobilisation in } 10 \text { degrees of external rotation using a sponge-covered wire mesh splint. } \\
\text { Group B: immobilisation in internal rotation using a sling and swathe. } \\
\text { Both groups received manual reduction (following X-ray if done at one of the study sites), } 3 \text { weeks } \\
\text { immobilisation apart from when taking a shower. Free movement of the arm on completion of the } \\
\text { immobilisation period. }\end{array}$ \\
\hline Outcomes & $\begin{array}{l}\text { Length of follow up: variable. Mean } 15.5 \text { months, } 14.7 \text { months for group A and } 16.9 \text { months for group } \\
\text { B. } \\
\text { (1) Self-reported redislocation (all participants; participants < } 30 \text { years; participants completing treatment) } \\
\text { (2) Apprehension test (only performed on people who had not redislocated) } \\
\text { (3) Return to pre-injury sport } \\
\text { (4) Non-compliance with immobilisation (premature removal of splintage at }<1 \text { week) }\end{array}$ \\
\hline Notes & $\begin{array}{l}\text { For the first version of the review, we have presented the results from the full trial report (2003). } \\
\text { The full trial report indicated that it was a preliminary study. A subsequent abstract (2004) stated it was } \\
\text { an interim report of an ongoing trial and referred to the random assignment of } 96 \text { patients, and reported } \\
\text { results for } 80 \text { participants. The inclusion criteria had changed in that patients with recurrent dislocations } \\
\text { were now included, but humeral fractures were explicitly excluded as were shoulders not immobilised } \\
\text { within } 3 \text { days of injury. The mean follow-up time in the } 2004 \text { abstract was } 12.4 \text { months. } \\
\text { Correspondence with Prof Itoi (July 2005) revealed the trial was still ongoing. Results for } 131 \text { participants } \\
\text { were reported at an Instructional Course Lecture (Principles and procedures for shoulder Instability: } \\
\text { An international perspective: Non-operative management of anterior instability)at the meeting of the } \\
\text { American Academy of Orthopaedic Surgeons in } 2005 \text {. (Handout provided to authors by Prof Itoi.) } \\
\text { There was no mention of who applied the splint - probably initially by orthopaedic surgeons. } \\
\text { No mention of method of determining the } 10 \text { degree angle of external rotation. }\end{array}$ \\
\hline
\end{tabular}

Risk of bias 
Itoi 2003 (Continued)

\begin{tabular}{l|ll}
\hline Item & Author' judgement & Description \\
\hline Allocation concealment? & No & C - Inadequate \\
\hline
\end{tabular}




\section{Characteristics of excluded studies [ordered by study ID]}

Harper 2000 There was no response to requests for information on this trial listed in the National Research Register UK. We found no other reports of this trial.

Hovelius 1983 This trial involved 27 centres. In six centres, allocation to two different durations of immobilisation was based on date of shoulder dislocation. In the other 21 centres, treatment was according to customary practice. Hence, overall this study was neither randomised or quasi-randomised.

Kiviluoto 1980 Of 99 people aged under 50 years in this study, 53 were immobilised for one week and 46 for three weeks. However, there was no indication of the method of allocation to the two groups, nor were results presented for these participants. We received no response from the trialists.

Staply 2002 A contact person in the institution given for this trial listed in the National Research Register UK indicated that her enquiries had indicated that this trial did not appear to have been started. We found no other reports of this trial.

Xu 2003

This was not a randomised controlled trial but a comparison, with a historical control group, of systematic rehabilitation therapy versus supporting bandage in 43 people with acute shoulder dislocation. 


\section{Characteristics of ongoing studies [ordered by study ID]}

\section{Itoi 2006}

\begin{tabular}{|c|c|}
\hline Trial name or title & What is the appropriate length of immobilization in external rotation after shoulder dislocation? \\
\hline \multicolumn{2}{|l|}{ Methods } \\
\hline Participants & 150 people with primary anterior shoulder dislocation \\
\hline Interventions & $\begin{array}{l}\text { (1) } 3 \text { weeks immobilisation in external rotation } \\
\text { (2) } 3 \text { weeks immobilisation in external rotation plus } 3 \text { weeks of elbow band (sling) } \\
\text { (3) } 3 \text { weeks immobilisation in external rotation plus } 6 \text { weeks of elbow band }\end{array}$ \\
\hline Outcomes & $\begin{array}{l}\text { Follow up: } 2 \text { years } \\
\text { Recurrence }\end{array}$ \\
\hline Starting date & November 2004 to November 2006 (recruitment period) \\
\hline Contact information & $\begin{array}{l}\text { Prof Itoi } \\
\text { Department of Orthopaedic Surgery } \\
\text { Akita University School of Medicine } \\
\text { Akita 010-8543 } \\
\text { Japan } \\
\text { E-mail: itoi@med.akita-u.ac.jp }\end{array}$ \\
\hline Notes & \\
\hline
\end{tabular}

\section{Pimpalnerker 2008}

Trial name or title A comparison study of internal versus external rotation immobilisation for primary anterior shoulder dislocation

\begin{tabular}{ll}
\hline Methods & \\
\hline Participants & 150 people with primary anterior shoulder dislocation \\
\hline Interventions & $\begin{array}{l}\text { (1) Arm immobilised in external rotation } \\
\text { (2) Arm immobilised in internal rotation }\end{array}$ \\
\hline Outcomes & $\begin{array}{l}\text { Follow up: not stated } \\
\text { Recurrence }\end{array}$ \\
\hline Starting date & January 2005 to May 2008 \\
\hline Contact information & $\begin{array}{l}\text { Mr Ashvin Pimpalnerker } \\
\text { Good Hope Hospital NHS Trust } \\
\text { Rectory Road } \\
\text { Sutton Coldfield } \\
\text { West Midlands } \\
\text { UK }\end{array}$
\end{tabular}




\section{Pimpalnerker 2008 (Continued)}

B75 7RR

Telephone: +44121378 2211

Notes Stated to be a randomised controlled trial

\section{Wakefield 2001}

\begin{tabular}{|c|c|}
\hline Trial name or title & The role of physiotherapy in the prevention of recurrence of anterior shoulder dislocation \\
\hline \multicolumn{2}{|l|}{ Methods } \\
\hline Participants & 23 people under 30 years of age with primary anterior shoulder dislocation (no fractures) \\
\hline Interventions & $\begin{array}{l}\text { (1) Intensive physiotherapy plus home exercises } \\
\text { (2) Home exercises alone }\end{array}$ \\
\hline Outcomes & $\begin{array}{l}\text { Follow up: } 18 \text { months } \\
\text { Redislocation rates and subsequent therapy, range of motion, muscle power, shoulder instability (Oxford } \\
\text { Shoulder Instability Score), pain. }\end{array}$ \\
\hline Starting date & October 1999 to October 2000 (recruitment period) \\
\hline Contact information & $\begin{array}{l}\text { Alison Wakefield } \\
\text { Research Physiotherapist } \\
\text { Trauma and Orthopaedics } \\
\text { F Level MP } 45 \\
\text { Southampton General Hospital } \\
\text { Tremona Rd } \\
\text { Southampton } \\
\text { UK } \\
\text { E-mail: awake@netmatters.co.uk }\end{array}$ \\
\hline Notes & $\begin{array}{l}\text { A draft report of the trial was shared with review authors in June 2005. It will be submitted for publication } \\
\text { in the next few months. }\end{array}$ \\
\hline
\end{tabular}


DATA AND ANALYSES

Comparison 1. Immobilisation in external versus internal rotation

\begin{tabular}{|c|c|c|c|c|}
\hline Outcome or subgroup title & $\begin{array}{l}\text { No. of } \\
\text { studies }\end{array}$ & $\begin{array}{c}\text { No. of } \\
\text { participants }\end{array}$ & Statistical method & Effect size \\
\hline 1 Non return to pre-injury sports & 1 & & Risk Ratio (M-H, Fixed, 95\% CI) & Totals not selected \\
\hline 2 Redislocation & 1 & & Risk Ratio (M-H, Fixed, 95\% CI) & Totals not selected \\
\hline $\begin{array}{l}3 \text { Instability: positive anterior } \\
\text { apprehension test or } \\
\text { redislocation }\end{array}$ & 1 & & Risk Ratio (M-H, Fixed, 95\% CI) & Totals not selected \\
\hline $\begin{array}{l}4 \text { Premature removal of } \\
\text { immobiliser }\end{array}$ & 1 & & Risk Ratio (M-H, Fixed, 95\% CI) & Totals not selected \\
\hline
\end{tabular}

\section{Analysis I.I. Comparison I Immobilisation in external versus internal rotation, Outcome I Non return to} pre-injury sports.

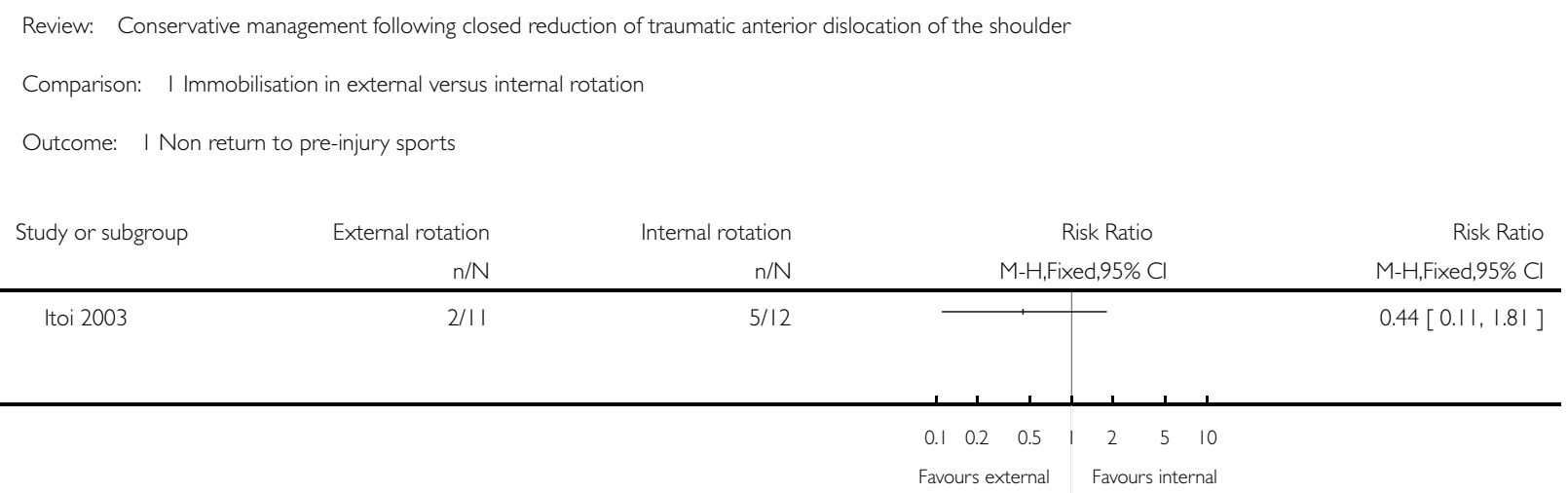


Analysis I.2. Comparison I Immobilisation in external versus internal rotation, Outcome 2 Redislocation. Review: Conservative management following closed reduction of traumatic anterior dislocation of the shoulder

Comparison: I Immobilisation in external versus internal rotation

Outcome: 2 Redislocation

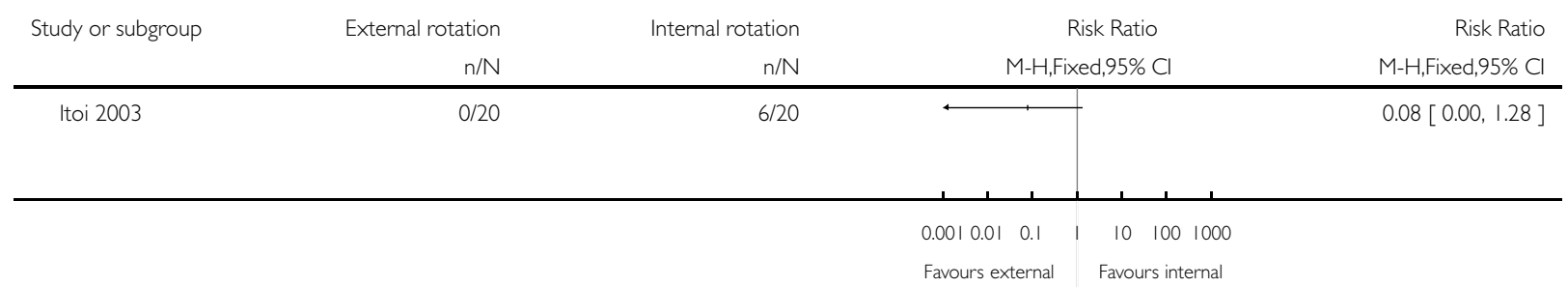

Analysis I.3. Comparison I Immobilisation in external versus internal rotation, Outcome 3 Instability: positive anterior apprehension test or redislocation.

Review: Conservative management following closed reduction of traumatic anterior dislocation of the shoulder

Comparison: I Immobilisation in external versus internal rotation

Outcome: 3 Instability: positive anterior apprehension test or redislocation

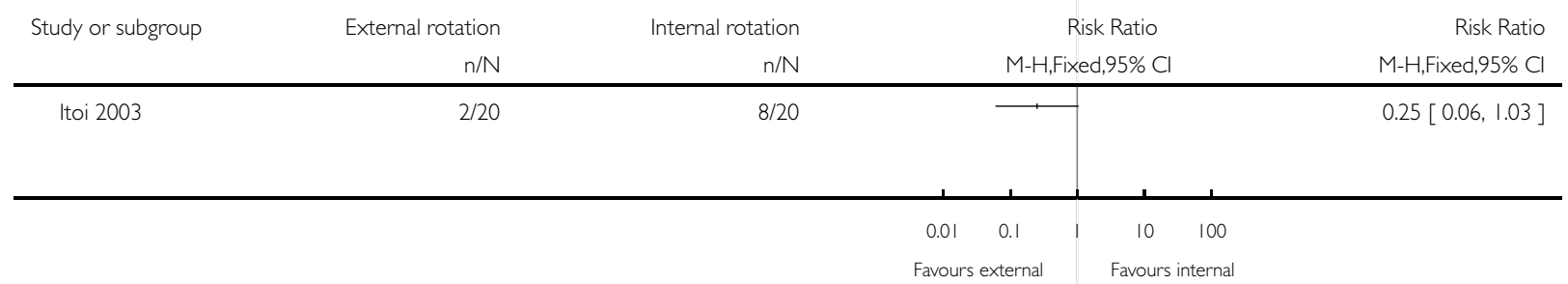


Analysis I.4. Comparison I Immobilisation in external versus internal rotation, Outcome 4 Premature removal of immobiliser.

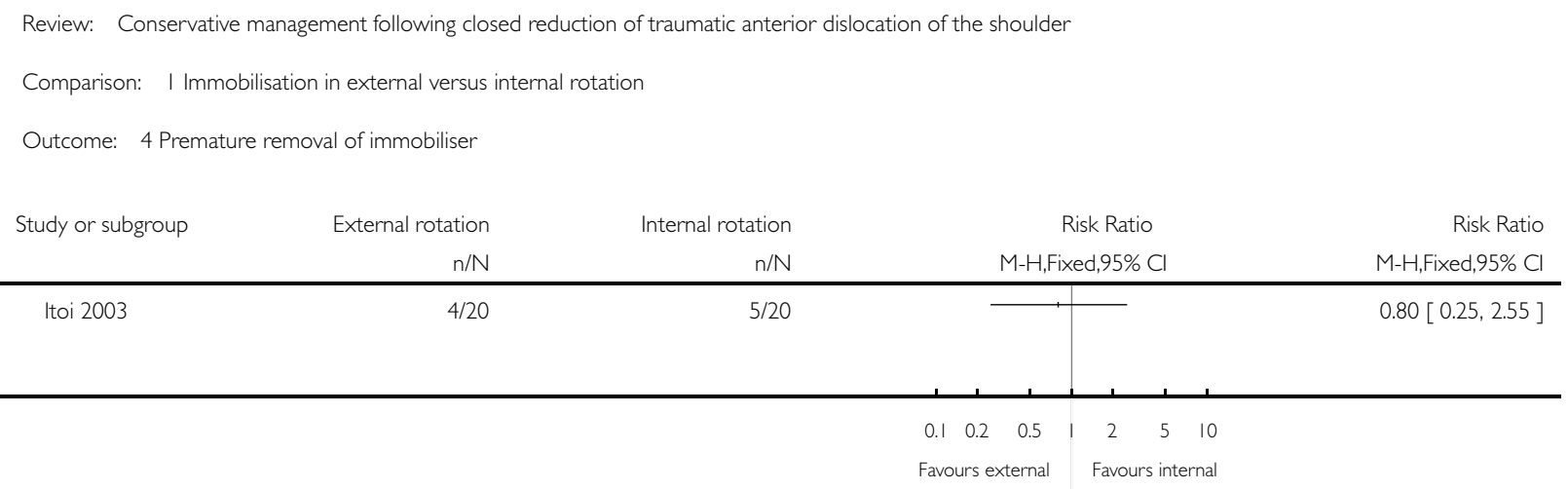

\section{A P P E N D I C E S}

\section{Appendix I. MEDLINE search strategy}

\section{MEDLINE (OVID WEB)}

1. Shoulder Dislocation/

2. (shoulder $\$$ adj3 (dislocat $\$$ or sublux $\$$ or instability or unstable)).tw.

3. (glenohumeral adj (joint or instability or unstable)).tw.

4. (lesion\$1 adj (Hill Sachs or Bankart)).tw.

5. or/ $1-4$

6. (immobilis $\$$ or immobiliz $\$$ or sling $\$$ or conservativ\$ or therap\$ or physiother $\$$ or rehabilitat $\$$ or mobilis $\$$ or mobiliz $\$$ or train $\$$ or exercis\$ or physical therap\$).tw.

7. Exercise/ or exp Rehabilitation/

8. (rh or th).fs.

9. or/6-8

10. and $/ 5,9$

11. randomized controlled trial.pt.

12. controlled clinical trial.pt.

13. Randomized Controlled Trials/

14. Random Allocation/

15. Double-Blind Method/

16. Single-Blind Method/

17. or/11-16

18. Animals/ not Human/

19. 17 not 18

20. clinical trial.pt.

21. exp Clinical Trials/

22. (clinic\$ adj25 trial\$).tw.

23. ((singl\$ or doubl\$ or trebl\$ or tripl\$) adj (mask\$ or blind\$)).tw. 


\section{(Continued)}
24. Placebos/
25 . placebo\$.tw.
26. random\$.tw.
27. Research Design/
28. (latin adj square).tw.
29. or $/ 20-28$
30. 29 not 18
31.30 not 19
32. or $/ 19,31$
33. and $/ 10,32$ 
Appendix 2. The Cochrane Library search strategy

\section{The Cochrane Library}

\#1. SHOULDER DISLOCATION single term (MeSH)

\#2. ((shoulder* near dislocat*) or (shoulder* near sublux*) or (shoulder* near instability)or (shoulder* near unstable))

\#3. ((glenohumeral next joint) or (glenohumeral next instability)or (glenohumeral next unstable))

\#4. ((lesion* next hill next sachs) or (lesion* next bankart))

\#5. (\#1 or \#2 or \#3 or \#4)

\#6. (immobilis* or immobiliz* or sling* or conservativ* or therap* or physiother* or rehabilitat* or mobilis* or mobiliz* or train* or exercis* $^{*}$ or (physical next therap*))

\#7. EXERCISE single term $(\mathrm{MeSH})$

\#8. REHABILITATION explode all trees (MeSH)

\#9. (\#6 or \#7 or \#8)

$\# 10$. (\#5 and \#9) 


\section{Appendix 3. EMBASE search strategy}

\section{EMBASE (OVID WEB)}

1. Shoulder Dislocation/or Bankart Lesion/

2. (shoulder\$ adj3 (dislocat\$ or sublux\$ or instability or unstable)).tw.

3. (glenohumeral adj (joint or instability or unstable)).tw.

4. (lesion\$1 adj (Hill Sachs or Bankart)).tw.

5. or/ $1-4$

6. (immobilis\$ or immobiliz\$ or sling $\$$ or conservativ\$ or therap\$ or physiother $\$$ or rehabilitat $\$$ or mobilis $\$$ or mobiliz $\$$ or train $\$$ or exercis\$ or physical therap\$).tw.

7. (rh or th).fs.

8. Conservative Treatment/or Physiotherapy/or exp Exercise/ or Rehabilitation/

9. or/6-8

10. and $/ 5,9$

11. exp Randomized Controlled trial/

12. exp Double Blind Procedure/

13. exp Single Blind Procedure/

14. exp Crossover Procedure/

15. Controlled Study/

16. or/11-15

17. ((clinical or controlled or comparative or placebo or prospective $\$$ or randomi\#ed)adj3 (trial or study)).tw.

18. (random\$ adj7 (allocat $\$$ or allot $\$$ or assign $\$$ or basis $\$$ or divid $\$$ or order $\$$ )).tw.

19. ((singl\$ or doubl\$ or trebl\$ or tripl\$) adj7 (blind $\$$ or mask $\$)$ ).tw.

20. (cross?over $\$$ or (cross adj1 over\$)).tw.

21. ((allocat $\$$ or allot $\$$ or assign $\$$ or divid $\$$ ) adj3 (condition $\$$ or experiment $\$$ or intervention $\$$ or treatment $\$$ or therap\$ or control\$ or group\$)).tw.

22. or/ $17-21$

23. or/ 16,22

24. limit 23 to human

25. and $/ 10,24$ 


\section{Appendix 4. CINAHL search strategy}

\section{CINAHL (OVID WEB)}

1. Shoulder Dislocation/

2. (shoulder\$ adj3 (dislocat\$ or sublux $\$$ or instability or unstable)).tw.

3. (glenohumeral adj (joint or instability or unstable)).tw.

4. (lesion $\$ 1$ adj (Hill Sachs or Bankart)).tw.

5. or/ $1-4$

6. (immobilis\$ or immobiliz\$ or sling\$ or conservativ\$ or therap\$ or physiother\$ or rehabilitat $\$$ or mobilis\$ or mobiliz\$ or train\$ or exercis\$ or physical therap\$).tw.

7. exp Rehabilitation/

8. (rh or th).fs.

9. or/6-8

10. and $/ 5,9$

11. exp Clinical Trials/

12. exp Evaluation Research/

13. exp Comparative Studies/

14. exp Crossover Design/

15. clinical trial.pt.

16. or/11-15

17. ((clinical or controlled or comparative or placebo or prospective or randomi\#ed)adj3 (trial or study)).tw.

18. (random\$ adj7 (allocat\$ or allot $\$$ or assign\$ or basis $\$$ or divid $\$$ or order $\$$ )).tw.

19. ((singl\$ or doubl\$ or trebl\$ or tripl\$) adj7 (blind $\$$ or mask $\$)$ ).tw.

20. (cross?over\$ or (cross adj1 over\$)).tw

21. ( (allocat $\$$ or allot\$ or assign\$ or divid\$) adj3 (condition\$ or experiment $\$$ or intervention $\$$ or treatment $\$$ or therap\$ or control\$ or group\$)).tw.

22. or/17-21

23. or/ 16,22

24. and $/ 10,23$

\section{WHAT'S NEW}

Last assessed as up-to-date: 3 November 2005.

5 September 2008 Amended Converted to new review format. 


\section{H I S T O R Y}

Protocol first published: Issue 4, 2004

Review first published: Issue 1, 2006

\section{CONTRIBUTIONS OFAUTHORS}

The protocol was developed by Nigel Hanchard (NH) and Helen Handoll (HH) with critical feedback from Lorna Goodchild (LG) and Joy Feary (JF). HH contacted trialists of eligible trials to inform choices for study inclusion and for extra information. All authors performed trial selection, quality assessment and data extraction. $\mathrm{HH}$ and $\mathrm{NH}$ compiled the first draft of the review with critical feedback from the LG and JF. Nigel Hanchard is the guarantor of the review.

\section{DECLARATIONS OF INTEREST}

None known.

\section{SOURCES OF SUPPORT}

\section{Internal sources}

- University of Teesside, Middlesbrough, UK.

\section{External sources}

- The Physiotherapy Research Foundation of the Chartered Society of Physiotherapy Charitable Trust (registered charity 279882), UK.

\section{NDEX TERMS}

\section{Medical Subject Headings (MeSH)}

Immobilization [adverse effects; methods]; Randomized Controlled Trials as Topic; Shoulder Dislocation [rehabilitation; *therapy]

\section{MeSH check words}

Humans 